\title{
The antiprotozoal drug pentamidine ameliorates experimentally induced acute colitis in mice
}

\author{
Giuseppe Esposito ${ }^{1 *}$, Elena Capoccia ${ }^{1}$, Giovanni Sarnelli ${ }^{2}$, Caterina Scuderi ${ }^{1}$, Carla Cirillo ${ }^{2,3}$, Rosario Cuomo ${ }^{2}$ \\ and Luca Steardo ${ }^{1}$
}

\begin{abstract}
Background: Intestinal inflammation is partly driven by enteroglial-derived S100B protein. The antiprotozoal drug pentamidine directly blocks S100B activity. We aimed to investigate the effect of pentamidine on intestinal inflammation using an animal model of dextran sodium sulphate (DSS)-induced acute colitis.

Methods: Mice were divided into: control group, colitis group (4\% DSS for four days) and two pentamidine-treated colitis groups $(0.8 \mathrm{mg} / \mathrm{kg}$ and $4 \mathrm{mg} / \mathrm{kg}$ ). Anti-inflammatory effect of pentamidine was assessed in colonic tissue by evaluating the disease activity index and the severity of histological changes. Colonic tissue were also used to evaluate cyclooxigenase-2, inducible nitric oxide synthase, S100B, glial fibrillary acidic protein, phosphorylated-p38 MAPkinase, p50, p65 protein expression, malondyaldheyde production, mieloperoxidase activity, and macrophage infiltration. Nitric oxide, prostaglandin $E_{2}$, interleukin-1 beta, tumor necrosis factor alpha, and S100B levels were detected in plasma samples. Parallel measurements were performed in vitro on dissected mucosa and longitudinal muscle myenteric plexus (LMMP) preparations after challenge with LPS + DSS or exogenous S100B protein in the presence or absence of pentamidine.
\end{abstract}

Results: Pentamidine treatment significantly ameliorated the severity of acute colitis in mice, as showed by macroscopic evaluation and histological/biochemical assays in colonic tissues and in plasma. Pentamidine effect on inflammatory mediators was almost completely abrogated in dissected mucosa but not in LMMP.

Conclusions: Pentamidine exerts a marked anti-inflammatory effect in a mice model of acute colitis, likely targeting S100B activity. Pentamidine might be an innovative molecule to broaden pharmacological tools against colitis.

Keywords: Pentamidine, Acute colitis, S100B protein, Enteric glia

\section{Background}

Although the etiology of ulcerative colitis (UC) remains incompletely understood, severe and persistent mucosal infiltration of macrophages and neutrophils in the large intestine represents a prominent feature [1]. Immune cells release cytokines, interleukins and proinflammatory signaling molecules [2-4]. In addition to the well-known involvement of macrophages and neutrophils, other cell types have been recently reported to substantially contribute to the onset and progression of the disease. Enteric glial cells (EGC) play a fundamental role in the maintenance of gut homeostasis since they have trophic

\footnotetext{
* Correspondence: giuseppe.esposito@uniroma1.it

'Department of Physiology and Pharmacology 'Vittorio Erspamer', University SAPIENZA of Rome, P. le Aldo Moro 5, 00185, Rome, Italy

Full list of author information is available at the end of the article
}

and protective functions toward enteric neurons and are fully implicated in the modulation of neuronal activities [5]. Moreover, EGC have been repeatedly reported to trigger and support intestinal inflammation [6] and to function as a first line of defense against pathogens [7]. EGC may proliferate and be activated in response to injury and inflammation undergoing reactive gliosis (enterogliosis), a condition in which they release neurotrophins, growth factors and proinflammatory cytokines cross-talking with other infiltrating immune cells [8]. Alterations in the homeostasis of the enteric nervous system are induced by reactive enterogliosis and are characterized by the massive overexpression and secretion of specific astroglial-derived signaling molecules such as S100B protein $[9,10]$.

S100B is a diffusible, $\mathrm{Ca}^{++} / \mathrm{Zn}^{++}$-p53 binding protein playing a pivotal role during intestinal inflammation,

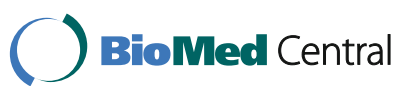


since it orchestrates proinflammatory signals [11,12]. Aberrant expression and release of S100B correlate with the inflammatory status of the gut. S100B accumulates at the RAGE (receptor for advanced glycation end products) site only in micromolar concentrations [11,13-15] and such interaction leads to mitogen-activated protein kinase (MAPK) phosphorylation and consequent nuclear factor-kappaB (NF-kB) activation, which, in turn, promote the transcription of different cytokines and inducible nitric oxide synthase (iNOS) protein [14]. Molecular targeting of S100B protein during intestinal inflammation might therefore represent an innovative approach to treat UC.

Pentamidine isethionate, discovered to have antiprotozoal activity in 1938, and approved in the United States for the treatment of Pneumocystis carinii pneumonia and other protozoal diseases [16], appears to be an intriguing candidate. In addition to its antiprotozoal activity, pentamidine has been reported to inhibit S100B activity because of its ability to block the interaction at the $\mathrm{Ca}^{++} / \mathrm{p} 53$ site of the protein [17].

Based on this background, the present study was aimed at evaluating the beneficial effect of a daily administration of pentamidine in an acute model of UC induced by dextran sulphate sodium (DSS) administration in drinking water in CD-1 mice. DSS-induced colitis is highly reproducible and is a well-known in vivo model of experimental colitis in rodents that reproduces many features of UC [18]. We tested the effect of pentamidine on (i) intensity of the symptoms (diarrhea, blood in the feces, animal weight loss) through a disease activity index (DAI) scale [19]; (ii) release of cytokines and proinflammatory signaling molecules present in mice plasma; (iii) postmortem evaluation of macroscopic shortening of large intestine and spleen weight; (iv) global colonic inflammation by the evaluation of biochemical and histological changes of the tissue.

\section{Methods}

\section{Animals and experimental design}

Six-weeks-old male CD-1 mice (25 to 35 g; Harlan Laboratories, Udine, Italy) were used for the experiments. Animals were randomly divided into five groups $(n=10$ each): noncolitic control group; colitic group; colitic group receiving daily pentamidine $0.8 \mathrm{mg} / \mathrm{kg}$; colitic group receiving daily pentamidine $4 \mathrm{mg} / \mathrm{kg}$; noncolitic group receiving daily pentamidine $4 \mathrm{mg} / \mathrm{kg}$ (as drug internal control). Colitis was induced by administrating DSS $(4 \% \mathrm{w} / \mathrm{v}, \mathrm{MW} 36,000$ to 50,000$)$ in drinking water for six consecutive days (starting from day 1 ), as described in Figure 1A. Pentamidine was given intraperitoneally starting at day 2 through day 6 . At day 7 , animals were sacrificed and tissues were removed to perform macroscopic, histochemical and biochemical analyses as described below.

\section{Disease activity index (DAI)}

The DAI scale is based on the evaluation of different parameters characterizing experimental colitis induction and progression. Body weight, presence of gross blood in the feces and stool consistency were recorded daily (from day 0 to 7 ) by an observer blinded to the treatment. According to the criteria proposed by Cooper et al. [19], the DAI was determined by scoring changes in: weight loss $(0=$ none; $1=1$ to $5 \% ; 2=5$ to $10 \% ; 3=$ 10 to $20 \% ; 4=>20 \%)$; stool consistency $(0=$ normal; $2=$ loose; $4=$ diarrhea $)$ and rectal bleeding $(0=$ normal; $2=$ occult bleeding; 4 =gross bleeding). At the end of the experiment, mice were sacrificed and colons and spleens were isolated to measure the length and weight of colon and spleen, respectively.

\section{Preparation of cytosolic extracts and western blot analysis}

Removed colonic tissues were processed for western blot analysis. Briefly, after homogenization in ice-cold hypotonic lysis buffer, protein concentration was determined using Bio-Rad protein assay kit (Bio-Rad, Milan, Italy). Analysis of cyclooxigenase (COX)-2, iNOS, TNF- $\alpha$, S100B, glial fibrillary acidic protein (GFAP), phosphorylated-p38 (p-p38) MAPK, p50, p65 and $\beta$-actin protein expression was performed on total protein fractions of homogenates. Equivalent amounts $(50 \mu \mathrm{g})$ of each homogenate underwent electrophoresis through a polyacrilamide minigel. Proteins were then transferred onto nitrocellulose membrane that were saturated by incubation with $10 \%$ nonfat dry milk in $1 \times \mathrm{PBS}$ overnight at $4^{\circ} \mathrm{C}$ and then incubated with either mouse anti-S100B (1:200 v/v, Neo-Marker, Milan, Italy), mouse anti-iNOS $(1: 2000 \mathrm{v} / \mathrm{v}, \mathrm{BD}$ Biosciences, Milan, Italy), rabbit anti-COX-2 (1:250 v/v, BD Biosciences), GFAP (1:5000 v/v, Abcam, Cambridge, UK), mouse anti-p50, mouse anti-p65 (1:1000 v/v, Santa Cruz Biotechnology, Santa Cruz, CA, USA), or mouse anti- $\beta$ actin (1:1,000 v/v, Santa Cruz Biotechnology) for $2 \mathrm{~h}$ at room temperature (RT). Membranes were then incubated with anti-mouse or anti-rabbit immunoglobulins coupled to peroxidase $(1: 2000 \mathrm{v} / \mathrm{v}$, Dako, Milan, Italy). Immune complexes were revealed by using enhanced chemiluminescence detection reagents (Amersham Biosciences, Milan, Italy) and exposed to Kodak X-Omat film (Eastman Kodak Co., Rochester, NY, USA OK). Protein bands were then scanned and densitometrically analyzed with a GS-700 imaging densitometer.

\section{Preparation of blood samples}

Before being sacrificed, mice were deeply anesthetized and the blood was taken by cardiac puncture and collected in 5\% EDTA vials. To determine nitric oxide (NO), prostaglandin E2 $\left(\mathrm{PGE}_{2}\right), \mathrm{IL}-1 \beta, \mathrm{TNF}-\alpha$, and S100B 

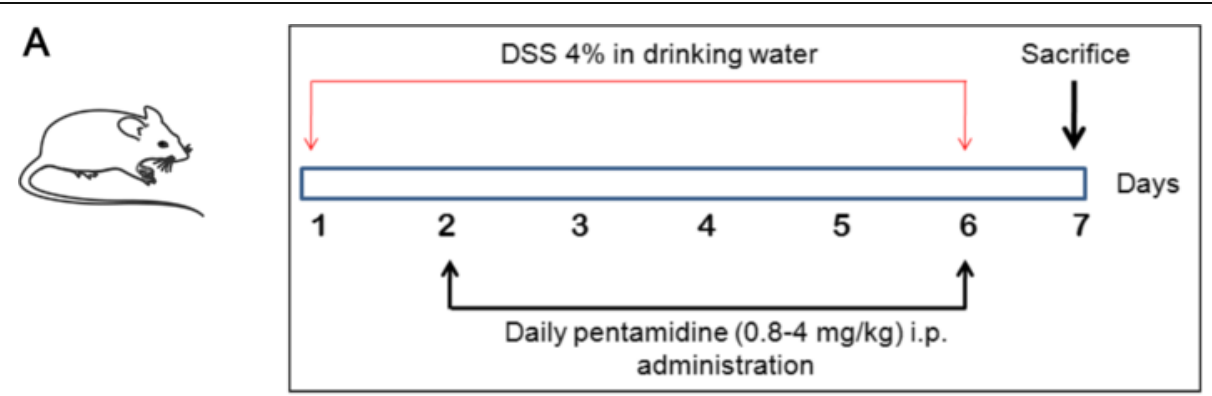

B



C
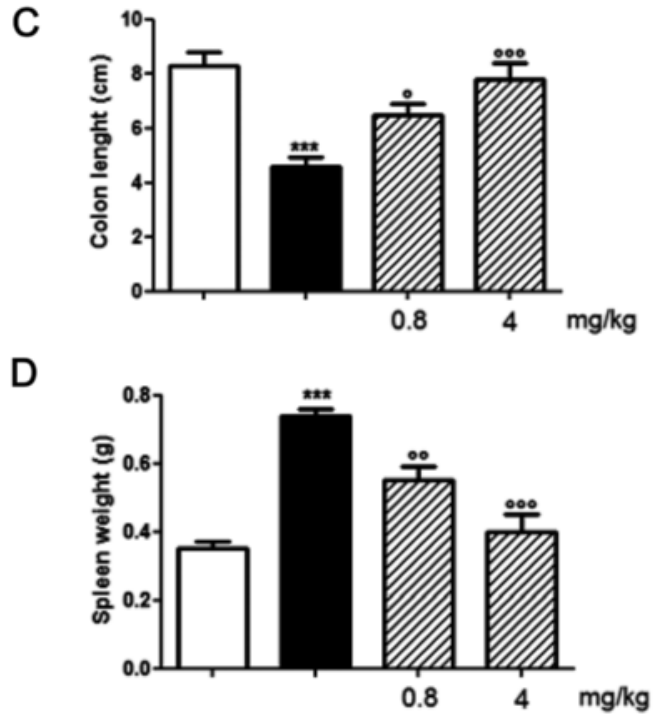

Figure 1 (A) Dextran sulphate sodium (DSS)-exposed (4\%) mice were treated daily with $0.8 \mathrm{mg} / \mathrm{kg}$ or $4 \mathrm{mg} / \mathrm{kg}$ pentamidine given intraperitoneally. Effect of pentamidine on (B) DAI score, (C) colonic length and (D) spleen weight in DSS-treated mice. Results are expressed as mean \pm SEM of $n=5$ experiments. ${ }^{* *} P<0.001$ vs. vehicle (saline); ${ }^{\circ} P<0.05 ;{ }^{\circ 0} P<0.01$ and ${ }^{\circ 00} P<0.001$ vs. DSS. DAl, disease activity index.

levels, plasma was isolated from the blood, immediately frozen, and stored at $-80^{\circ} \mathrm{C}$ until the assays.

\section{Plasma NO quantification}

$\mathrm{NO}$ was measured as nitrite $\left(\mathrm{NO}_{2}^{-}\right)$accumulation in plasma. A spectrophotometer assay based on the Griess reaction was used [20]. Briefly, Griess reagent (1\% sulphanilamide, $0.1 \%$ naphthylethylenediamine in $\mathrm{H}_{3} \mathrm{PO}_{4}$ ) was added to an equal volume of plasma and the absorbance was measured at $550 \mathrm{~nm} . \mathrm{NO}_{2}^{-}$concentration $(\mathrm{nM})$ was thus determined using a standard curve of $\mathrm{NaNO}_{2}$.
Plasma PGE 2 , TNF- $\alpha, \mathrm{S} 100 \mathrm{~B}$, and IL-1 $\beta$ quantification

Quantitative determination of $\mathrm{PGE}_{2}$, IL- $1 \beta$, TNF- $\alpha$, and $\mathrm{S} 100 \mathrm{~B}$ was carried out performing enzyme linkedimmunosorbent assay (ELISA) on plasma samples $\left(\mathrm{PGE}_{2}, \mathrm{TNF}-\alpha, \mathrm{IL}-1 \beta\right.$ kits were from Invitrogen, Milan, Italy; S100B kit was from BioVendor, Heidelberg, Germany) according to the manufacturer's kit instructions.

\section{Macrophage infiltration in the mucosa}

Samples for immunohistochemical assessment were isolated from distal colon and fixed in $4 \%$ paraformaldehyde, 
embedded in paraffin, sectioned in $15 \mu \mathrm{m}$ slices and processed for immunohistochemistry. Slices were pretreated for 20 min using heat-mediated antigen retrieval with a sodium citrate buffer, incubated with MAC387 [21] $(1 \mu \mathrm{g} / \mathrm{ml}$, Abcam) for $15 \mathrm{~min}$ at RT, and detected using horseradish peroxidase (HRP)-conjugated compact polymer system. DAB was used as the chromogen. Slices were then counterstained with hematoxylin, mounted with Eukitt and analyzed with a microscope (Nikon Eclipse 80i by Nikon Instruments Europe, Amstelveen, Netherlands). Images were captured by a high-resolution digital camera (Nikon Digital Sight DS-U1).

\section{p53 Immunofluorescence}

Colon slices derived from both control and treated mice were blocked in $10 \%$ bovine serum albumin $0.1 \%$ Triton-PBS solution for $90 \mathrm{~min}$ at RT and subsequently stained for $1 \mathrm{~h}$ at RT with anti-p53 antibody (1:1250, Santa Cruz Biotechnology) and anti-MAC387 (1:200, Abcam). Sections were then incubated for $1 \mathrm{~h}$ at RT in the dark with the proper secondary antibody: fluorescein isothiocyanate-conjugated anti-rabbit (1:100, Abcam) or Texas Red-conjugated anti-mouse (1:64, Abcam), respectively. Nuclei were stained with Hoechst (1:5000, Sigma-Aldrich, Milan, Italy). Slides were thus analyzed with a microscope (Nikon Eclipse 80i by Nikon Instruments Europe), and images were captured at 10X and 20X magnification by a high-resolution digital camera (Nikon Digital Sight DS-U1).

\section{Myeloperoxidase (MPO) assay}

MPO, a marker of polymorphonuclear leukocyte accumulation and general inflammation occurring in colonic tissue, was determined as previously described [22]. After removal, colonic tissue was rinsed with cold saline, opened and deprived from the mucosa using a glass slide. The resulting layer was then homogenized in a solution containing $0.5 \%$ hexadecyltrimethylammonium bromide dissolved in $10 \mathrm{mM}$ potassium phosphate buffer $(\mathrm{pH} 7.0)$ and centrifuged for $30 \mathrm{~min}$ at $20000 \times \mathrm{g}$ at $37^{\circ} \mathrm{C}$. An aliquot of the supernatant was mixed with a solution of tetramethylbenzidine $(1.6 \mathrm{mM})$ and $0.1 \mathrm{mM}$ $\mathrm{H}_{2} \mathrm{O}_{2}$. The absorbance was then spectrophotometrically measured at $650 \mathrm{~nm}$. MPO activity was determined as the amount of enzyme degrading $1 \mathrm{mmol}$ of peroxide per minute at $37^{\circ} \mathrm{C}$ and was expressed in milliunits per $100 \mathrm{mg}$ of wet tissue weight.

\section{Lipid peroxidation assay}

Malonyl dialdehyde (MDA) was measured by the thiobarbituric acid colorimetric assay [23] in colonic tissue. Briefly, $1 \mathrm{~mL} \mathrm{10 \%} \mathrm{(w/v)} \mathrm{trichloroacetic} \mathrm{acid} \mathrm{was} \mathrm{added}$ to $450 \mu \mathrm{l}$ of tissue lysate. After centrifugation, $1.3 \mathrm{~mL}$ $0.5 \%(\mathrm{w} / \mathrm{v})$ thiobarbituric acid was added and the mixture was heated at $80^{\circ} \mathrm{C}$ for $20 \mathrm{~min}$. After cooling, MDA formation was recorded (absorbance $530 \mathrm{~nm}$ and absorbance $550 \mathrm{~nm}$ ) in a Perkin Elmer (Waltham, MA, USA) spectrofluorimeter and the results were presented as ng MDA/mL.

\section{Mucosa and LMMP preparations}

In order to further evaluate the putative site and the mechanism of action of pentamidine, additional experiments were set up as follows. Colonic segments (approximately $1.5 \mathrm{~cm}$ long) were isolated from another set of CD-1 mice not previously used for any in vivo treatment. Mice were euthanized by injection of pentobarbital sodium $(100 \mathrm{mg} / \mathrm{kg})$ and distal colon was removed and cut longitudinally to expose the mucosa. Under sterile conditions, the tissues were placed in Dulbecco's modified Eagle's medium (supplemented with 5\% fetal bovine serum, $2 \mathrm{mM}$ glutamine, $100 \mathrm{U} / \mathrm{mL}$ penicillin, $100 \mu \mathrm{g} / \mathrm{mL}$ streptomycin, all from Invitrogen), pinned flat and the mucosa was carefully peeled off to obtain the longitudinal muscle-myenteric plexus (LMMP) layer [24]. Depending upon the experimental plan, both mucosa and LMMP were stimulated for $24 \mathrm{~h}$ with exogenous lipopolysaccharide (LPS) $(10 \mu \mathrm{g} / \mathrm{ml})+$ DSS $(1 \% \mathrm{w} / \mathrm{v})$ or exogenous S100B (5 $\mu \mathrm{M}$, Sigma-Aldrich, Milan, Italy), with or without the addition of pentamidine (0.5 to $5 \mu \mathrm{M})$ administered to the tissue $10 \mathrm{~min}$ prior to LPS + DSS or S100B stimulus.

\section{Statistical analysis}

Results were expressed as mean \pm SEM of experiments. Statistical analysis was performed using parametric oneway analysis of variance (ANOVA) and multiple comparisons were performed by Bonferroni's post hoc test. $P$ values $<0.05$ were considered significant.

\section{Results}

\section{Pentamidine ameliorates DAI score, preserves colonic} length and reduces splenomegaly induced by DSS

Starting from day 4 after DSS administration, DAI score was significantly increased in DSS groups. As expected, DSS caused a consistent increase in bloody diarrhea together with loss of body weight, as compared to control group (Figure 1B). DSS also caused a significant shortening of colon and a marked increase of spleen weight (Figure $1 \mathrm{C}$ and D). Pentamidine treatment inhibited the rise in DAI score in a dose-dependent way, suggesting an overall improvement of intestinal symptoms associated with colitis after DSS administration; such effect was accompanied by a reduction of bloody stools, diarrhea frequency, and a rescue of body weight (Figure 1B). Moreover, pentamidine was able to preserve colonic length and to prevent splenomegaly in DSS-treated mice (Figure $1 \mathrm{C}$ and $\mathrm{D}$ ). 
Pentamidine inhibits intestinal inflammation induced by DSS

In Figure 2 it is shown that the administration of DSS caused a marked increase of iNOS, COX-2, S100B and GFAP protein expression compared to control mice. Pentamidine treatment resulted in a dose-dependent attenuation of iNOS, COX-2 and GFAP but not of S100B protein overexpression (Figure 2A and B). As expected, Griess reaction and ELISA demonstrated that the administration of DSS caused a significant increase in plasma $\mathrm{NO}_{2}^{-}$level, PGE 2 IL-1 $\beta$, TNF- $\alpha$ and S100B, compared to control mice (Figure 3 ). Also in this case and according to western blot results, pentamidine treatment caused a marked and dose-dependent attenuation of all the inflammatory mediators in plasma, except for S100B release that remained unaffected after pentamidine treatment.

Pentamidine inhibits S100B-induced lipid peroxidation, p38 MAPK phosphorylation, and NF-KB activation induced by DSS

Further characterizing the inhibitory effect of pentamidine, we found that in DSS-treated mice the increase in $\mathrm{S100B}$ expression was accompanied by a significant increase in lipid peroxidation and phosphorylation of p38 MAPK (Figure 4A and B). These effects were related to both p50 and p65 protein overexpression and indicated the activation of NF- $\mathrm{KB}$ (Figure $4 \mathrm{~B}$ ). In our experimental conditions, pentamidine significantly and dose-dependently inhibited MDA accumulation, p38 MAPK phosphorylation and, consequently, NF-kB activation.

\section{Pentamidine reduces DSS-induced macrophage infiltration and MPO activity}

Colonic mucosa was extensively infiltrated by macrophages in DSS-treated mice compared to control mice (Figure 5A and B). Such increase was accompanied as well by neutrophil infiltration, as showed by the increased MPO activity (Figure 5C). Pentamidine treatment caused a significant and dose-dependent reduction in macrophage infiltration together with significant and dosedependent inhibition of MPO activity, indicating that pentamidine is able to control neutrophil infiltration in colonic tissues (Figure 5A and B).
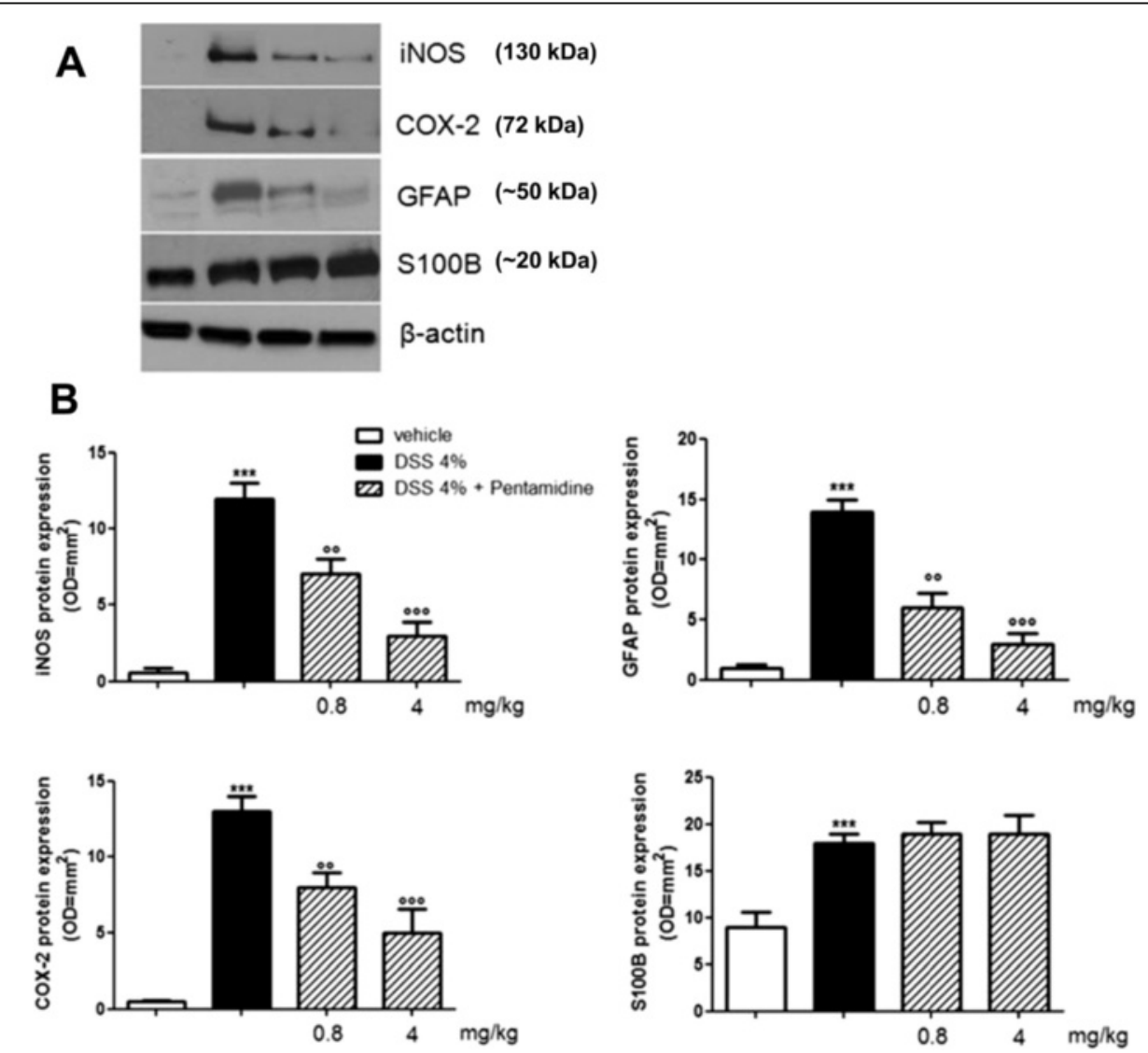

Figure 2 (A) Western blot analysis showing the effect of pentamidine on iNOS, COX-2, GFAP and S100B protein expression in colonic tissue of DSS-treated mice; (B) relative quantification of immunoreactive bands (arbitrary units). Results are expressed as mean \pm SEM of $n=5$ experiments performed in triplicate. ${ }^{* * *} P<0.001$ vs. vehicle (saline); ${ }^{\circ 0} p<0.01$ and ${ }^{\circ 00} P<0.001$ vs. DSS. COX2, cyclooxigenase-2; DSS, dextran sodium sulphate; GFAP, glial fibrillary acidic protein; iNOS, inducible nitric oxide synthase. 


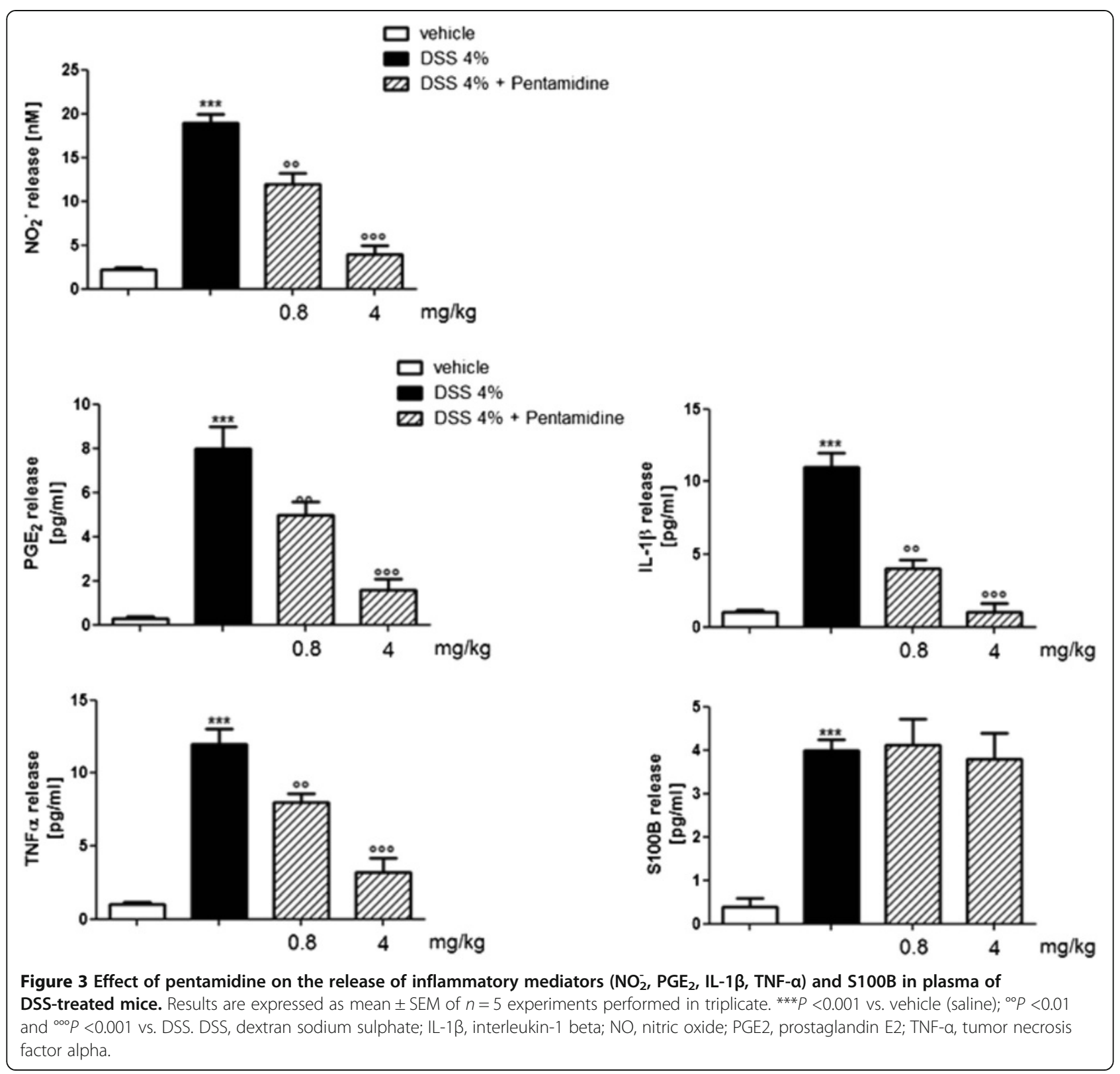

\section{Pentamidine induces p53 expression in infiltrating macrophages}

Macrophage infiltration in the colonic tissues from DSS-treated mice was confirmed by immunofluorence (Figure 6A). Pentamidine treatment significantly and dosedependently reduced macrophage infiltration (Figure 6A). Very interestingly, such decrease was accompanied by the reverse trend in p53 expression. In fact, p53 resulted negative in the colon from control and DSS-treated mice, while a strong immunopositivity was found in colonic tissues from pentamidine-treated mice (Figure 6). Moreover, p53 expression was found in macrophages, as revealed from the co-expression with MAC387, a specific macrophage marker [21] (Figure 6).

\section{S100B-dependent effect of pentamidine}

An internal check for the expression of S100B protein was performed in both mucosal and LMMP preparations confirming that the protein was expressed exclusively in the LMMP layer (Figure 7A). Preparations were separately challenged with DSS (1\%) plus LPS $(1 \mu \mathrm{g} / \mathrm{ml})$ or S100B $(5 \mu \mathrm{M})$ in the presence or absence of pentamidine (0.5 to $5 \mu \mathrm{M})$. Stimulation with LPS + DSS caused a marked proinflammatory response in the mucosa as well as in LMMP preparations, as demonstrated by the increase in nitrites level, $\mathrm{PGE}_{2}$ and TNF- $\alpha$ level compared to respective nonstimulated preparations (Figure $7 \mathrm{~B}$ and C). Very interestingly, pentamidine had no significant beneficial effect on the mucosa while it significantly and 

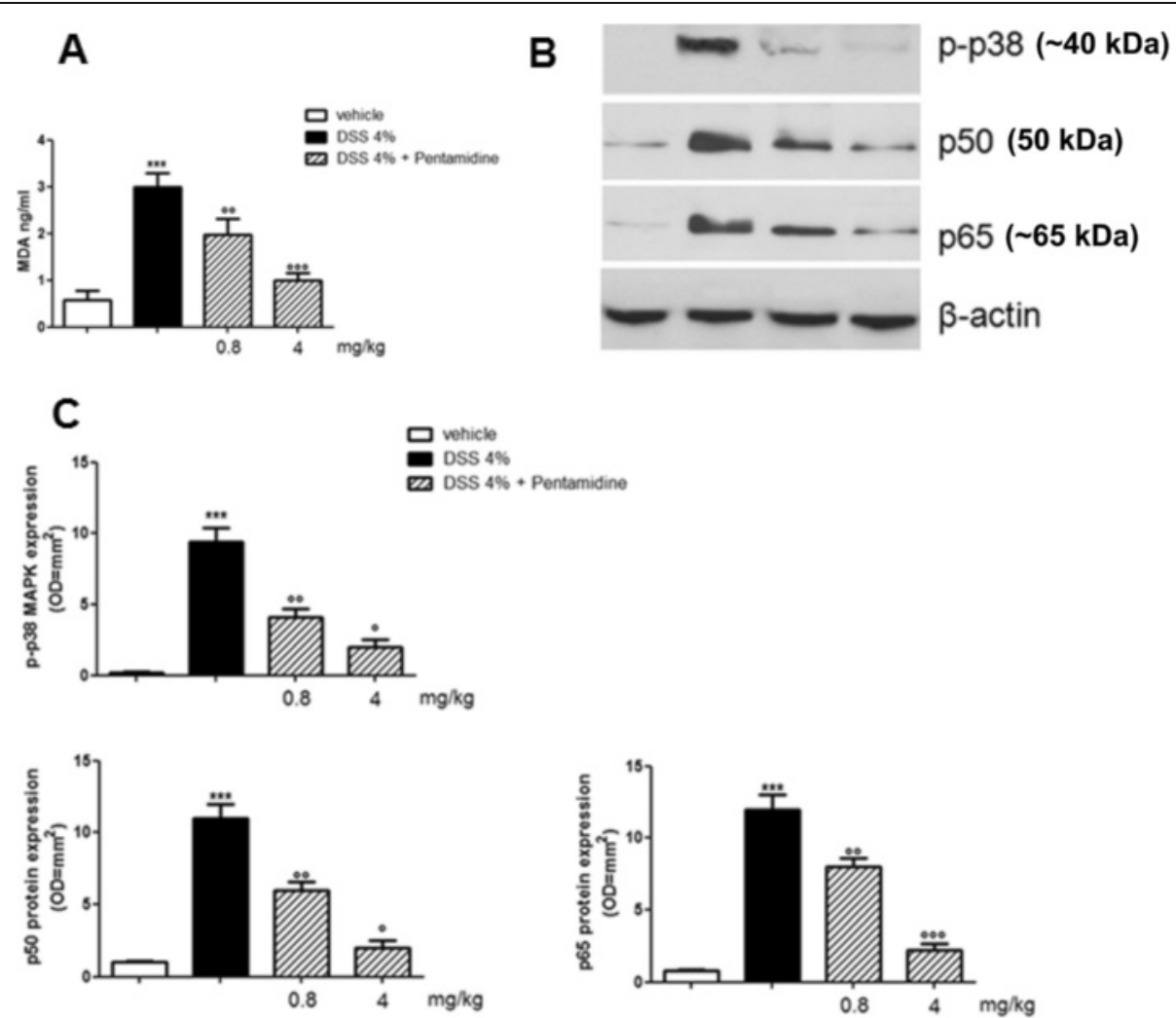

Figure 4 (A) Effect of pentamidine on MDA production in colonic tissue of DSS-treated mice; (B) immunoblots showing the effect of pentamidine on p-p38 MAPK, p50 and p65 protein expression in colonic tissue of DSS-treated mice; (C) relative quantification of immunoreactive bands. Results are expressed as mean \pm SEM of $n=5$ experiments performed in triplicate. ${ }^{* *} P<0.001$ vs. vehicle (saline); ${ }^{\circ} P<0.05,{ }^{\circ} P<0.01$ and ${ }^{\circ 00} P<0.001$ vs. DSS. DSS, dextran sodium sulphate; MDA, malondialdehyde; $p$-p38 MAPK, phosphorylated-p38 MAPkinase.

concentration-dependently reduced the release of nitrites, $\mathrm{PGE}_{2}$ and TNF- $\alpha$ in LMMP preparations (Figure 7C). Exogenous application of $\mathrm{S} 100 \mathrm{~B}$ to the mucosa caused a significant increase in nitrites, $\mathrm{PGE}_{2}$, and TNF- $\alpha$ level (Figure 7B). As confirmation for the S100B-dependent effect, pretreatment with pentamidine significantly and concentration-dependently reduced S100B-induced inflammation in the mucosa (Figure 7C).

\section{Discussion}

The results of the present study indicate that pentamidine is capable to profoundly and beneficially impact on an animal model of acute colitis. The model we used has been demonstrated to resemble UC features [18]. Prevailing therapies for UC include chronic administration of glucocorticosteroids and mesalamine [25,26]. Steroids are effective in the short-term treatment of acute flares of UC but they are not suitable as a maintenance therapy due to a variety of systemic adverse reactions [27]. Sulfasalazine and its derivative 5-aminosalicylic acid are effective only in mild-to-moderate acute phase of the disease and in preventing relapse. Biological drugs such as monoclonal anti-TNF- $\alpha$ antibody (infliximab and adalimumab) have been recently introduced in the therapy of relapsing inflammatory bowel disease with encouraging results in the maintenance of remission [28]. However, the long-term safety of these drugs, the possibility to induce severe side effects [29-31] together with the high costs of the therapy for the patients warrant novel and alternative pharmacological approaches.

We demonstrated that pentamidine efficiently and dose-dependently improved colitis. It caused attenuation of the DAI together with preservation of colonic length and reduction of splenomegaly induced by DSS-colitis. Besides inducing such macroscopic beneficial effects, treatment with pentamidine also resulted in microscopic amelioration of intestinal inflammation as demonstrated by the reduction of MPO activity, a marker of tissue neutrophils activation, and of macrophage mucosal infiltration. Very interestingly, we found that the treatment with pentamidine induced p53 expression on infiltrating macrophages. We know that S100B inhibits p53 activity and that pentamidine inhibits S100B overexpression. Thus, we may speculate that pentamidine, through the 

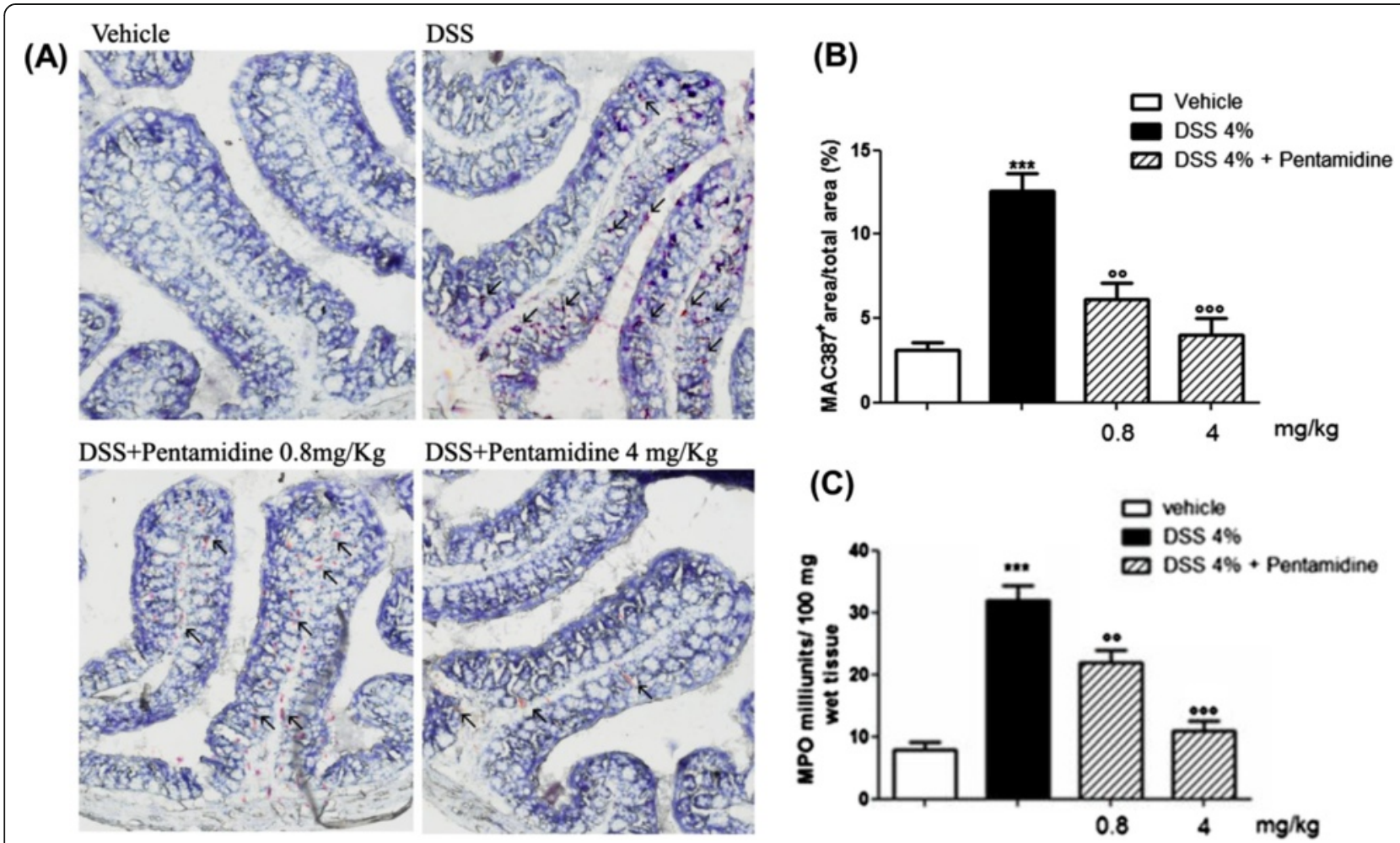

Figure 5 (A) Effect of pentamidine on macrophage infiltration in colonic tissue of DSS-treated mice: pentamidine dose-dependently reduced macrophages infiltration. Arrows indicate MAC387 immunopositive macrophages infiltrating colon criptae; (B) Quantification of MAC387 immunopositive macrophages in colon criptae. Data are expressed as mean \pm SEM of $n=3$ experiments; (C) effect of pentamidine on MPO level in colonic tissue of DSS-treated mice. Results are expressed as mean \pm SEM of $n=6$ experiments. ${ }^{* * *} P<0.001$ vs. vehicle (saline);

${ }^{\circ 0} p<0.01$ and ${ }^{\circ 00} p<0.001$ vs. DSS. Original magnification 100X. DSS, dextran sodium sulphate; MPO, mieloperoxidase.

inhibition of S100B, induces p53 expression indirectly driving macrophages apoptosis. This trend could also explain the anti-inflammatory effect exerted by pentamidine.

As expected, DSS treatment caused a marked increase in COX-2 and iNOS protein expression in the colon accompanied by a significant release of $\mathrm{PGE}_{2}$ and $\mathrm{NO}$ in the plasma. Such increase was significantly and dosedependently reduced by pentamidine treatment. We previously demonstrated that during intestinal inflammation, S100B rises up to micromolar concentrations, further amplifying inflammatory responses $[6,8,12]$. In these conditions, S100B induces lipid peroxidation and activates p38 MAPK phosphorylation leading, in turn, to NF-KB activation and proinflammatory cytokines release. Here again, we report that pentamidine treatment resulted in a significant inhibition of lipid peroxidation, p38MAPK activation and relative stabilization of NF- $\mathrm{kB}$ in the cytoplasm by targeting S100B activity. These results further confirm that pentamidine, by interfering at the p53 binding site on S100B protein, drastically reduces inflammatory events induced by S100B, leading to the overall improvement of intestinal inflammation.
Given the well-described inhibitory effect exerted by pentamidine on S100B activity [17], we evaluated whether it could negatively control enteric gliosis, thus exerting a negative modulation of intestinal inflammation. The administration of DSS demonstrated an enormous increase of both S100B and GFAP protein expression. Pentamidine was not capable of negatively modulating S100B protein expression in tissues and its release in plasma, while it was able to induce a significant decrease in GFAP protein expression. This data could be explained by the fact that since pentamidine inhibits the activity but not the expression/release of S100B [17], this drug may prevent the downstream effects due to the over-release of S100B during intestinal inflammation. In an autocrine manner, S100B induces proliferation of glial cells and, thus, increase in GFAP expression. We can thus speculate that pentamidine, by the inhibition of S100B activity, may control glial proliferation as highlighted by the decrease in GFAP expression. Alternatively, the ability of pentamidine to significantly reduce the expression of GFAP may be secondary to the reduced levels of inflammatory 

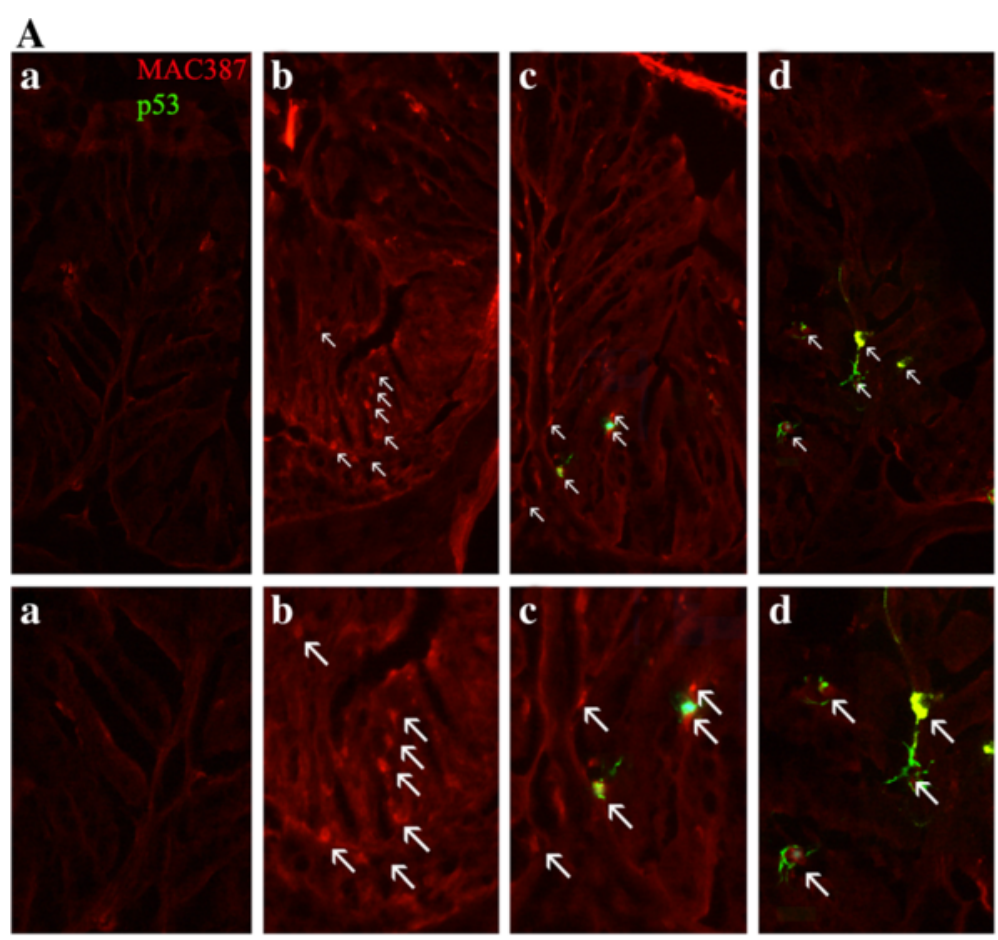

B
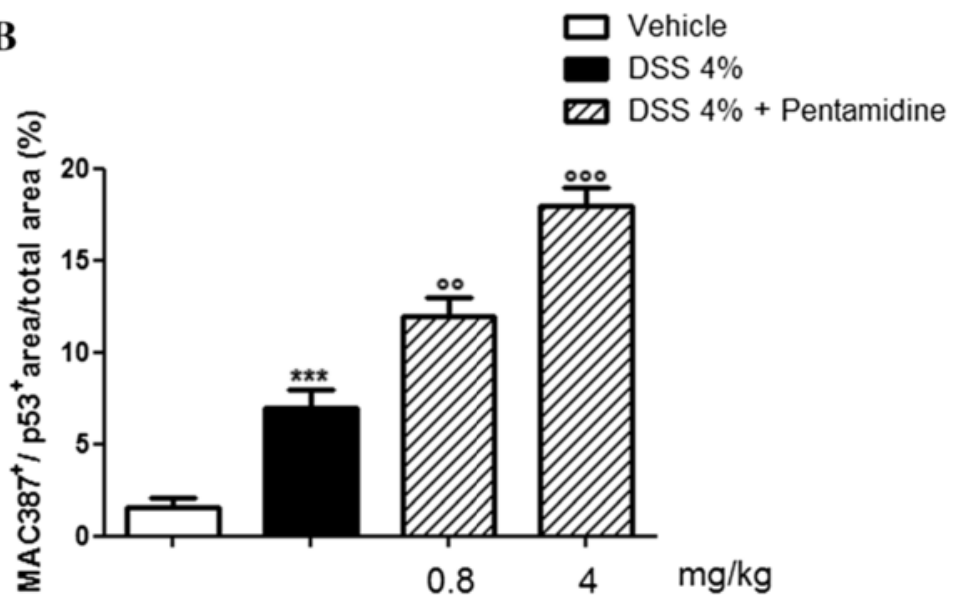

Figure 6 (A) Immunofluorescence analysis of colonic tissues showing the effect of pentamidine on macrophage infiltration induced by DSS: pentamidine dose-dependently inhibited macrophage infiltration (MAC387, red) and increased p53 expression (green) in colon criptae. Arrows indicate MAC387/p53 co-expression; (B) relative quantification (MAC387+/p53 + area/total area percentage) of macrophage infiltration and p53 expression in DSS-treated mice. Data are expressed as mean \pm SEM of $n=3$ experiments. Original magnification 200X. DSS, dextran sodium sulphate.

cytokines that have been previously demonstrated to drive glial proliferation [32].

Since S100B release has been reported to increase macrophage activity causing proinflammatory responses [33], we wondered whether the anti-inflammatory effect exerted by pentamidine on acute intestinal inflammation could be the result of the direct targeting of S100B in the glial network or the consequence of the indirect effect on infiltrating immune cells in the mucosa. We used organotypic cultures of isolated mucosa or LMMP preparations [24] and we challenged them with DSS plus LPS in the presence or absence of pentamidine. Our results demonstrated that pentamidine was able to significantly and concentration-dependently inhibit LPS + DSS-induced $\mathrm{NO}_{2}^{-}, \mathrm{PGE}_{2}, \mathrm{IL}-1 \beta$ and TNF- $\alpha$ release in LMMP but not in mucosal preparations. This result suggests that pentamidine needs S100B to exert its antiinflammatory properties. To confirm such hypothesis, 




we challenged mucosa preparations with exogenous $\mathrm{S} 100 \mathrm{~B}$ in the presence or absence of pentamidine. Interestingly, we found that pentamidine significantly reversed S100B-induced release of inflammatory mediators, thus demonstrating that anti-inflammatory properties of pentamidine are dependent on S100B.

\section{Conclusions}

Pentamidine may be putatively proposed as a new drug able to control the acute phase of intestinal inflammation, likely by acting on glial activation and thus inhibiting the deleterious cascade induced by S100B protein. Because of its well-known pharmacological and toxicological profile, 
at present, pentamidine might be regarded as a potential, innovative, manageable, and low-cost tool against colitis.

\section{Abbreviations}

COX2: cyclooxigenase-2; DAl: disease activity index; DSS: dextran sodium sulphate; EGC: enteric glial cells; GFAP: glial fibrillary acidic protein; IL$1 \beta$ : interleukin-1 beta; iNOS: inducible nitric oxide synthase; LMMP: longitudinal muscle-myenteric plexus; LPS: lipopolysaccharide; MDA: malonyldialdehyde; MPO: mieloperoxidase; NF-KB: nuclear factorkappaB; NO: nitric oxide; PGE2: prostaglandin E2; p-p38 MAPK: phosphorylated-p38 MAPkinase; RAGE: receptor for advanced glycation end products; TNF-a: tumor necrosis factor alpha; UC: ulcerative colitis.

\section{Competing interests}

All authors declare that they have no competing interest.

\section{Authors' contribution}

GE and EC conceived the study; GE designed experiments; EC performed experiments; GS and CC analyzed the data and contributed to the critical revision of the research plan; CS collected the data. GE, LS and RC equally contributed to the design of the study and writing and final approval of the manuscript. All authors read and approved the final manuscript.

\section{Acknowledgements}

The authors thank Dr. Daniele De Filippis and Prof. Teresa luvone for their precious help in editing the manuscript.

\section{Author details}

'Department of Physiology and Pharmacology 'Vittorio Erspamer', University SAPIENZA of Rome, P. le Aldo Moro 5, 00185, Rome, Italy. ²Department of Clinical and Experimental Medicine, University of Naples FEDERICO II, Via S. Pansini 5, 80131, Naples, Italy. ${ }^{3}$ Current address: Laboratory for Enteric NeuroScience (LENS), TARGID, KU Leuven, Herestraat 49, 3000, Leuven, Belgium

Received: 26 September 2012 Accepted: 19 November 2012 Published: 23 December 2012

\section{References}

1. Monteleone G, Pallone F, MacDonald T: Emerging immunological targets in inflammatory bowel disease. Curr Opin Pharmacol 2011, 11:640-645.

2. Helper DJ, Rex DK: Inflammatory bowel disease. Endoscopy 2001, 33:140-146.

3. Reinders $\mathrm{Cl}$, Herulf M, Ljung T, Hollenberg J, Weitzberg E, Lundberg JO Hellström PM: Rectal mucosal nitric oxide in differentiation of inflammatory bowel disease and irritable bowel syndrome. Clin Gastroenterol Hepatol 2005, 3:777-783.

4. Hendel J, Nielsen $\mathrm{OH}$ : Expression of cyclooxygenase-2 mRNA in active inflammatory bowel disease. Am J Gastroenterol 1997, 92:1170-1173

5. Ruhl A, Nasser Y, Sharkey KA: Enteric glia. Neurogastroenterol Motil 2004, 16:44-49.

6. Cirillo C, Sarnelli G, Esposito G, Turco F, Steardo L, Cuomo R: S100B protein in the gut: the evidence for enteroglial-sustained intestinal inflammation. World J Gastroenterol 2011, 17:1261-1266.

7. Collins SM, Bercik P: The relationship between intestinal microbiota and the central nervous system in normal gastrointestinal function and disease. Gastroenterology 2009, 136:2003-2014.

8. De Filippis D, Esposito G, Cirillo C, Cipriano M, De Winter BY, Scuderi C, Sarnelli G, Cuomo R, Steardo L, De Man JG, luvone T: Cannabidiol reduces intestinal inflammation through the control of neuroimmune axis. PLoS One 2011, 6:e28159.

9. Cirillo C, Sarnelli G, Esposito G, Grosso M, Petruzzelli R, Izzo P, Calì G, D'Armiento FP, Rocco A, Nardone G, luvone T, Steardo L, Cuomo R: Increased mucosal nitric oxide production in ulcerative colitis is mediated in part by the enteroglial-derived S100B protein. Neurogastroenterol Motil 2009, 21:1209-e112.
10. von Boyen GB, Schulte N, Pflüger C, Spaniol U, Hartmann C, Steinkamp M: Distribution of enteric glia and GDNF during gut inflammation. BMC Gastroenterol 2011, 11:3.

11. Cirillo C, Sarnelli G, Turco F, Mango A, Grosso M, Aprea G, Masone S, Cuomo $\mathrm{R}$ : Proinflammatory stimuli activates human-derived enteroglial cells and induces autocrine nitric oxide production. Neurogastroenterol Motil 2011, 23:e372-e382

12. Esposito G, Cirillo C, Sarnelli G, De Filippis D, D'Armiento FP, Rocco A, Nardone G, Petruzzelli R, Grosso M, Izzo P, luvone T, Cuomo R: Enteric glialderived S100B protein stimulates nitric oxide production in celiac disease. Gastroenterology 2007, 133:918-925

13. Adami C, Bianchi R, Pula G, Donato R: S100B-stimulated NO production by BV-2 microglia is independent of RAGE transducing activity but dependent on RAGE extracellular domain. Biochim Biophys Acta 2004, 1742:169-177.

14. Hofmann MA, Drury S, Fu C, Qu W, Taguchi A, Lu Y, Avila C, Kambham N, Bierhaus A, Nawroth $P$, Neurath MF, Slattery T, Beach D, McClary J, Nagashima M, Morser J, Stern D, Schmidt AM: RAGE mediates a novel proinflammatory axis: a central cell surface receptor for S100/calgranulin polypeptides. Cell 1999, 97:889-901.

15. Schmidt AM, Yan SD, Yan SF, Stern DM: The multiligand receptor RAGE as a progression factor amplifying immune and inflammatory responses. J Clin Invest 2001, 108:949-955.

16. Pearson RD, Hewlett EL: Pentamidine for the treatment of Pneumocystis carinii pneumonia and other protozoal diseases. Ann Intern Med 1985, 103:782-786

17. Charpentier TH, Wilder PT, Liriano MA, Varney KM, Pozharski E, MacKerell AD Jr, Coop A, Toth EA, Weber DJ: Divalent metal ion complexes of $\mathrm{S} 100 \mathrm{~B}$ in the absence and presence of pentamidine. J Mol Biol 2008, 382:56-73.

18. Park MY, Ji GE, Sung MK: Dietary kaempferol suppresses inflammation of dextran sulfate sodium-induced colitis in mice. Dig Dis Sci 2012, 57:355-363.

19. Cooper HS, Murthy SN, Shah RS, Sedergran DJ: Clinicopathologic study of dextran sulfate sodium experimental murine colitis. Lab Invest 1993, 69:238-249.

20. Di Rosa M, Radomski M, Carnuccio R, Moncada S: Glucocorticoids inhibit the induction of nitric oxide synthase in macrophages. Biochem Biophys Res Commun 1990, 172:1246-1252.

21. Thoree V, Skepper J, Deere H, Pele LC, Thompson RP, Powell JJ: Phenotype of exogenous microparticle-containing pigment cells of the human Peyer's patch in inflamed and normal ileum. Inflamm Res 2008, 57:374-378.

22. Mullane KM, Kraemer R, Smith B: Myeloperoxidase activity as a quantitative assessment of neutrophil infiltration into ischemic myocardium. J Pharmacol Methods 1985, 14:157-167.

23. Mihara $M$, Uchiyama M: Determination of malonaldehyde precursor in tissues by thiobarbituric acid test. Anal Biochem 1978, 86:271-278.

24. Kindt S, Vanden Berghe P, Boesmans W, Roosen L, Tack J: Prolonged IL1 beta exposure alters neurotransmitter and electrically induced $\mathrm{Ca}(2+)$ responses in the myenteric plexus. Neurogastroenterol Motil 2010, 22:321-e85.

25. Ford AC, Bernstein CN, Khan KJ, Abreu MT, Marshall JK, Talley NJ, Moayyedi P: Glucocorticosteroid therapy in inflammatory bowel disease: systematic review and meta-analysis. Am J Gastroenterol 2011, 106:590-599.

26. Ford AC, Achkar JP, Khan KJ, Moayyedi P: Efficacy of 5-aminosalicylates in ulcerative colitis: systematic review and meta-analysis. Am J Gastroenterol 2011, 106:601-616.

27. Cottone M, Renna S, Modesto I, Orlando A: Is 5-ASA still the treatment of choice for ulcerative colitis? Curr Drug Targets 2011, 12:1396-1405.

28. Rutgeerts $P$, Vermeire $S$, Van Assche G: Biological therapies for inflammatory bowel diseases. Gastroenterology 2009, 136:1182-1197.

29. Fok KC, Ng WW, Henderson CJ, Connor SJ: Cutaneous sarcoidosis in a patient with ulcerative colitis on infliximab. J Crohns Colitis 2012, 6:708-712.

30. Kinnunen U, Färkkilä M, Mäkisalo $\mathrm{H}$ : A case report: Ulcerative colitis, treatment with an antibody against tumor necrosis factor (infliximab), and subsequent liver necrosis. J Crohns Colitis 2012, 6:724-727.

31. Huang $X, L V B$, Jin HF, Zhang S: A meta-analysis of the therapeutic effects of tumor necrosis factor-a blockers on ulcerative colitis. Eur J Clin Pharmacol 2011, 67:759-766. 
32. von Boyen GB, Steinkamp M, Reinshagen M, Schäfer KH, Adler G, Kirsch J: Proinflammatory cytokines increase glial fibrillary acidic protein expression in enteric glia. Gut 2004, 53:222-228.

33. Esposito G, De Filippis D, Cirillo C, Sarnelli G, Cuomo R, luvone T: The astroglial-derived S100beta protein stimulates the expression of nitric oxide synthase in rodent macrophages through p38 MAP kinase activation. Life Sci 2006, 78:2707-2715.

doi:10.1186/1742-2094-9-277

Cite this article as: Esposito et al.: The antiprotozoal drug pentamidine ameliorates experimentally induced acute colitis in mice. Journal of Neuroinflammation 2012 9:277.

\section{Submit your next manuscript to BioMed Central and take full advantage of:}

- Convenient online submission

- Thorough peer review

- No space constraints or color figure charges

- Immediate publication on acceptance

- Inclusion in PubMed, CAS, Scopus and Google Scholar

- Research which is freely available for redistribution 